\title{
Aggression rate in acute inpatient psychiatric units: impact of substance abuse and psychosis
}

\begin{abstract}
Introduction: Reduction of aggression rate is a major challenge in acute inpatient psychiatric units and may adversely affect the wellbeing of both staff and patients. The lifetime risk for assault on nurses working on inpatient psychiatric units has been reported to be approximately $75 \%$. The efficacy of current risk assessment strategies in lowering incidence of violence on acute inpatient psychiatry units is still unclear.

Methods: 63 Electronic Medical Records were retrospectively reviewed for violent and aggressive incidents reported by the staff over a six-month period in acute inpatient adult psychiatry units.

Results: A total of 73 aggressive incidents were reported of which 39 (53\%) were patient-on-patient and $16(20 \%)$ patient-on-staff. The highest risk factors for being involved in an aggressive incident included, a) male gender b) schizoaffective and schizophrenia diagnosis c) substance use disorder. Approximately 50\% of patients involved in aggressive actions had a secondary diagnosis of substance use disorders.

Conclusion: The data suggest that the majority of aggressive behaviors on inpatient units are patient-on-patient. At least $50 \%$ of the individuals involved in aggressive behavior have a secondary diagnosis of substance use disorder.
\end{abstract}

Keywords: aggression, violence, inpatient unit, psychiatric
Volume 3 Issue I - 2017

\author{
Tolulope Olupona, Inderpreet Virk, Adenike \\ Ishola, Evaristo Akerele \\ Department of Psychiatry, USA
}

Correspondence: Inderpreet Virk, Department of Psychiatry, Interfaith Medical Center 1545 Atlantic Avenue, Brooklyn, N.Y, II2 |3, USA, Tel (I) 669-226-I57I, Fax 7|8-228-7907,

Email inderpreetsvirk@yahoo.com

Received: August 29, 2016 | Published: February 15, 2017
Abbreviations: ECA, epidemiologic catchment area; NIMH, national institute of mental health; EMR, electronic medical records

\section{Introduction}

Aggression refers to range of behaviors that can result in both physical and psychological harm to oneself, others or objects in the environment. In patients with psychiatric disorders, there is an increased risk of aggression compared with the general population. In the Epidemiologic Catchment Area (ECA) study, the lifetime prevalence of violence among people with serious mental illness was $16 \%$, as compared to $7 \%$ among people without mental illness. ${ }^{1}$ Aggressive behavior is one of the primary reasons for admission to psychiatric inpatient units. It can occur verbally, physically or mentally. It is a common problem in acute psychiatric inpatient units and can put both the healthcare provider and patient at risk. ${ }^{2,3}$ This may result in low performance and low morale in the staff, impacting the quality of care resulting in a vicious cycle. ${ }^{4-6}$ It is estimated that between $8 \%-44 \%$ of patients are aggressive during their stay on psychiatric inpatient units which vary widely ${ }^{7,8}$ and $10 \%-30 \%$ of hospitalized psychiatric patients have engaged in violence prior to admission. ${ }^{9,10}$ Data suggest that $75 \%$ of nursing staff have been assaulted by patients in acute psychiatric inpatient units. ${ }^{11}$ Multiple risk factors have been shown to be associated with aggression in inpatient units but the strategies to help prevent and manage aggression and their effectiveness needs to be studied and established.

In this retrospective study, we report aggression rate in acute inpatient adult psychiatric units at a busy urban community hospital and try to identify the high risk factors associated with aggression.

\section{Methods}

Data from the hospital's Electronic Medical Records was retrospectively reviewed. The number of violent and aggressive incidents reported by the staff over period of six months in the acute inpatient adult psychiatric units was noted. This included, but was not limited to physical assaults and verbal altercations between patient to patient, patient to staff, and property damage secondary to aggressive behavior. Aggression rate was calculated by dividing the total number of aggressive behavior incident reports for those 6 months from total patient days at a given month X 100. Demographic variables were assessed and compared within the six-month period to establish the risk factors in our study. Table 1 shows the demographic characteristics of our patients which included age, sex, diagnosis, substance use disorder and violence.

Table I Demographic variables $(n=63)$

\begin{tabular}{lll}
\hline & Variable & Frequency \\
\hline Sex & Male & 44 \\
& Female & 19 \\
\hline Diagnosis & & \\
\hline & Schizoaffective & 33 \\
& Schizophrenia & 15 \\
& Bipolar Type I & 9 \\
MDD & 2 \\
Psychotic Disorder NOS & I \\
MDD with psychosis & I \\
Brief psychotic disorder & I \\
Psychosis due to steroid & I \\
Substance abuse & 37 \\
History of violence & 17
\end{tabular}




\section{Results}

Of the 73 aggressive incidents reported, 39 were due to physical assaults between patient to patient, 16 directed towards the staff, ${ }^{12}$ due to verbal altercation and 6 resulted in property damage secondary to aggressive behavior. During the six-month period, aggression rate was less than $1 \%$ with mean of 0.49 and range $0.15-0.82$. Figure 1 shows the aggression rates for the 6 months. Aggression rates were found to be higher among men compared to females ( $70 \%$ vs. $30 \%)$. The rates of aggression by sex shown in Figure 2. Most patients were between the ages of 18 and 70 years, with a mean of 32. Patients who had diagnosis of schizoaffective and schizophrenia were more likely to be aggressive compared to other psychiatric disorders (Figure 3). Substance abuse was seen in $59 \%$ of our patients while $27 \%$ had a prior history of violence.

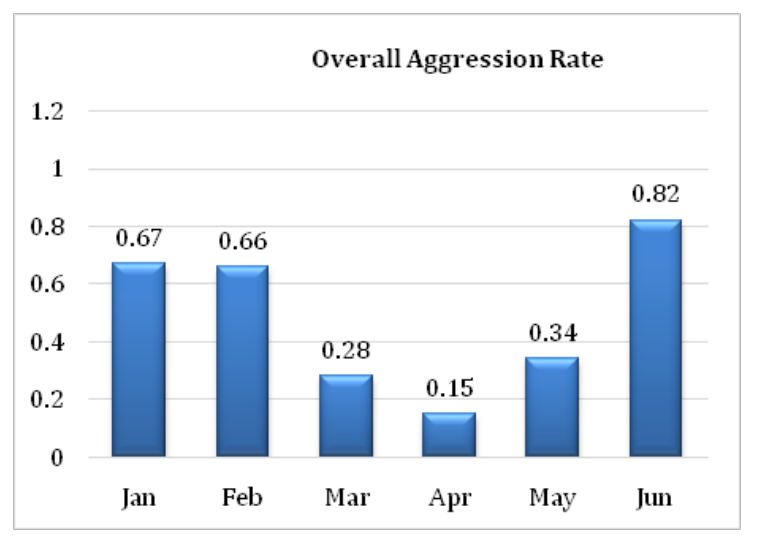

Figure I Overall Aggregation Rate.

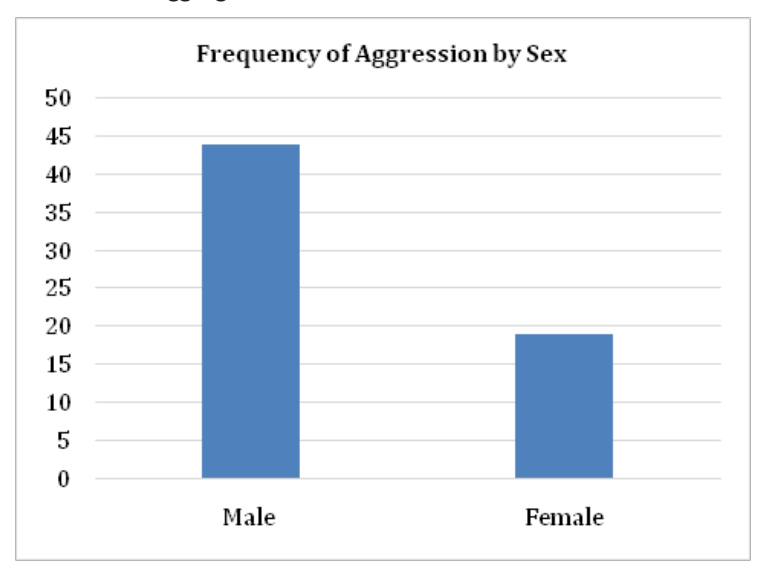

Figure 2 Frequency of Aggression by Sex.

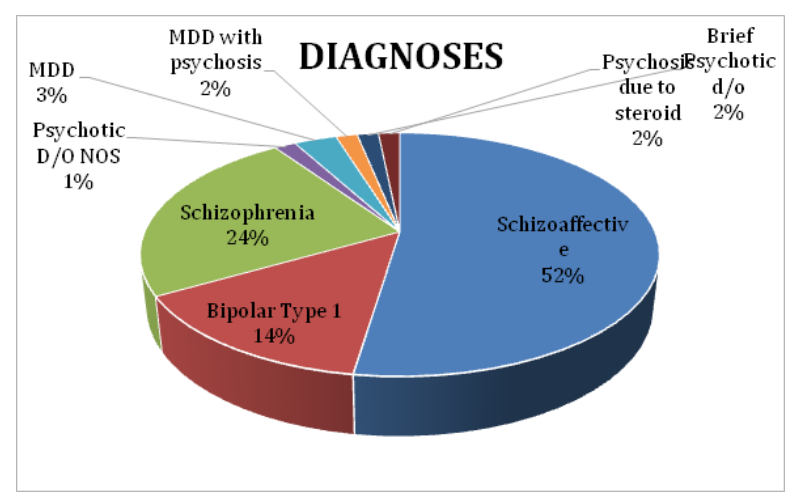

Figure 3 Diagnoses.

\section{Discussion}

The data suggest that the patient to patient and patient to staff physical assaults are the most frequent form of aggression which is consistent with other studies..$^{13,14}$ Other risk factors for aggression identified included gender (male), having a diagnosis of schizoaffective disorder and schizophrenia, history of substance abuse which is also one of the most common risk factors associated with aggression outside of hospitals. Lozzino et al. ${ }^{11}$ in a systematic review of the literature reached similar conclusions. Our data suggest that having any form of psychotic diagnosis is associated with higher risk for aggression. This is also supported by Faulkner et al. ${ }^{15}$ which indicated that 72 percent of assaultive patients were individuals with schizophrenia or some other psychotic disorder. According to National Institute of Mental Health (NIMH), in their Epidemiologic Catchment Area (ECA) study, patients with schizophrenia, major depression or bipolar disorder were two to three times as likely to be assaultive. Being a male was a high risk factor in our study (70\%) for aggression on inpatient psychiatric units. However some studies suggest that there is no significant difference between men and women in the likelihood of aggression on the inpatient psychiatry unit. Tardiff et al. ${ }^{16} \&$ Lam et al. ${ }^{12}$ found that female patients were as likely as male patients to become violent in an inpatient setting. Furthermore, Krakowski \& Czobor $^{17}$ also investigated gender differences in violent behaviors among psychiatric inpatients, and concluded that it was equal in both men and women 15. The total number of aggressive incidents reported in our study over six months was comparatively less compared to other studies done in the community hospitals. Some of the reasons could be due to the short period of time, small sample size and more corrective actions taken to reduce aggression rate within the hospital. Some of the corrective actions taken included but not limited to periodic staff meetings, crisis prevention training, securing either of the patient to avoid escalation, panic buttons, case conferences, early application for court medication order for noncompliant patients, BROSET score assessment and timely intervention, enforced and enhanced individual safety plan, identifying the risk factors of violence and individual behavioral plan for aggressive patients, use of de-escalation techniques and pharmacotherapy. There are a number of limitations in this study.

1. This was a retrospective study so there was no control group.

2. The sample size was small and was dependent on the data reported by staff in the Electronic Medical Records and the variation in physician documentation could be a confounding factor.

3. The tendency to underreport aggression incidents on inpatient units.

\section{Conclusion}

Aggression occurring in inpatient psychiatric units is a significant public health issue. Hospitals need to ensure that aggression management strategies are in place and periodically identify and assess the level of risk. Studies should be conducted with a large sample size to measure rates of violence and establish the risk factors for aggression in acute psychiatric inpatients in order to develop strategies to help prevent and manage violence in psychiatric units. More data is needed especially from within the country to directly compare findings and achieve the benchmark.

\section{Acknowledgements}

None. 


\section{Conflict of interest}

The author declares no conflict of interest.

\section{References}

1. United States Department of Health and Human Services. Epidemiologic Catchment Area Study 1980-1985. USA: National Institute of Mental Health; 2011.

2. Kafantaris V, Lee D, Magee H, et al. Assessment of children with the overt aggression scale. J Neuropsychiatry Clin Neurosci. 1996;8(2):186193

3. Wistedt B, Rasmussen A, Pedersen L, et al. The Development of an Observer-Scale for Measuring Social Dysfunction and Aggression. Pharmacopsychiatry. 1990;23(6):249-252.

4. Daffern M, Mayer M, Martin T. Staff gender ratio and aggression in a forensic psychiatric hospital. Int J Ment Health Nurs. 2006;15(2):93-99.

5. Fisher WA. Elements of Successful Restraint and Seclusion Reduction Programs and Their Application in a Large, Urban, State Psychiatric Hospital. J Psychiatr Pract. 2003;9(1):7-15.

6. Needham I, Abderhalden C, Halfens R, et al. The effect of a training course in aggression management on mental health nurses' perceptions of aggression: A cluster randomised controlled trial. Int J Nurs Stud. 2005;42(6):649-655.

7. Palmstierna T, Wistedt B. Staff observation aggression scale, SOAS Presentation and evaluation. Acta Psychiatr Scand. 1987;76(6):657-663.

8. Nijman $\mathrm{H}$, Palmstierna $\mathrm{T}$. Measuring aggression with the staff observation aggression scale-revised. Acta Psychiatr Scand Suppl. 2002;106(S412):101-102.
9. Yudofsky S, Silver J, Jackson W, et al. The Overt Aggression Scale for the objective rating of verbal and physical aggression. Am J Psychiatry. 1986;143(1):35-39.

10. Silver J, Yudofsky S. The Overt Aggression Scale: overview and guiding principles. J Neuropsychiatry Clin Neurosci. 1991;3(2):22S-29S.

11. Iozzino L, Ferrari C, Large M, et al. Prevalence and Risk Factors of Violence by Psychiatric Acute Inpatients: A Systematic Review and Meta-Analysis. PLoS One. 2015;10(6):e0128536.

12. Lam JN, Mcniel DE, Binder RL. The Relationship Between Patients' Gender and Violence Leading to Staff Injuries. Psychiatr Serv. 2000;51(9):1167-1170.

13. Owen C, Tarantello C, Jones M, et al. Violence and Aggression in Psychiatric Units. Psychiatr Serv. 1998;49(11):1452-1457.

14. Barlow K, Grenyer B, Ilkiw Lavalle O. Prevalence and precipitants of aggression in psychiatric inpatient units. Aust NZ J Psychiatry. 2000;34(6):967-974

15. Faulkner LR, Grimm NR, McFarland BH, et al. Threats and assaults against psychiatrists. Bull Am Acad Psychiatry Law. 1990;18(1):37-46.

16. Tardiff K, Marzuk P, Leon A, et al. Violence by patients admitted to a private psychiatric hospital. Am J Psychiatry. 1997;154(1):88-93.

17. Krakowski M, Czobor P. Gender differences in violent behaviors: relationship to clinical symptoms and psychosocial factors. $A m J$ Psychiatry. 2004;161(3):459-465. 